\title{
Characterization of IGV-Rotor Interactions in a Pre-Whirl Axial Fan
}

\author{
ADEL GHENAIET ${ }^{1}$
}

${ }^{1}$ Laboratory of Energetics and Conversion Systems, Faculty of Mechanical Engineering, University of Sciences and Technology, Houari Boumediene, BP 32 El-alia, Bab-ezzouar, 16111, Algiers, Algeria

May 5, 2020

\begin{abstract}
The main goal of this study is to determine the aerodynamic performance and to characterize unsteady flows in a high-speed high-reaction pre-whirl axial flow fan. The pressure waves' main diametrical modes where two blades interact with two vanes and their sequences are predicted. There are mainly two mechanisms of IGV-rotor interactions identified; the first is attributed to the potential effect whereas the second is due to the wake-blade interaction and the advection of wake mixing into the blades' passages. Both effects are dependent on the circumferential positions of blades and the axial inter-distance between IGV and rotor. The time mode analyses of pressure fluctuations recorded from different monitor points are determined and the frequencies of prevailing modes and those related to the vortical flow structure through the components are also identified. The understanding of vanes and blade rows interactions at various axial inter-distances is an important step in determining the beneficial and detrimental effects on the design of high performance axial fan stage.
\end{abstract}

\section{Hosted file}

Draft Paper_Fan_RS [30-01-2020].pdf available at https://authorea.com/users/295369/ articles/424982-characterization-of-igv-rotor-interactions-in-a-pre-whirl-axial-fan 